\title{
From advanced disease to transplantation: an overview of the liver at the time of COVID-19 pandemic
}

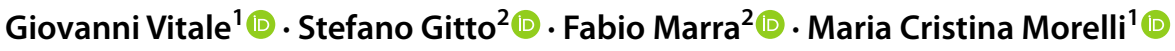

Received: 24 June 2021 / Accepted: 1 July 2021 / Published online: 10 July 2021

(c) Società Italiana di Medicina Interna (SIMI) 2021

\begin{abstract}
In 2020, the severe acute respiratory syndrome coronavirus 2 (SARS-CoV-2) also known as coronavirus disease 2019 (COVID-19) disrupted global health, causing hundreds of thousands of deaths worldwide. The liver injury appears to be one of the possible systemic manifestations of COVID-19 disease although the mechanisms causing such injury are not entirely clear. At the beginning of the pandemic, patients with chronic diseases, such as liver cirrhosis, or special populations, such as liver transplant recipients, were considered at higher risk of complications and poor clinical outcomes. Thus, the national transplant programmes have been severely hampered by the COVID-19 pandemic. Furthermore, liver transplant patients are potentially more vulnerable to SARS-CoV-2 infection due to immune suppression, ageing, and metabolic or cardiovascular comorbidities. This review analyses the increasing amounts of data collected in recent months concerning liver cirrhosis and liver transplants to understand if this finding is still relevant with respect to COVID-19 manifestations.
\end{abstract}

Keywords Liver transplantation · Liver disease · SARS-CoV-2 · COVID-19 · Liver cirrhosis · Immunosuppressive treatment

$\begin{array}{ll}\text { Abbreviations } & \\ \text { ACE2 } & \text { Angiotensin-converting enzyme 2 } \\ \text { ACLD } & \text { Advanced chronic liver disease } \\ \text { BAL } & \text { Broncho-Alveolar Lavage } \\ \text { CLD } & \text { Chronic liver disease } \\ \text { COVID-19 } & \text { Coronavirus Disease 2019 } \\ \text { CsA } & \text { Cyclosporin A } \\ \text { FU } & \text { Follow-up } \\ \text { HCC } & \text { Hepatocellular carcinoma }\end{array}$

Giovanni Vitale

giovanni.vitale@aosp.bo.it

Stefano Gitto

stefano.gitto@unifi.it

Fabio Marra

fabio.marra@unifi.it

Maria Cristina Morelli

mariacristina.morelli@aosp.bo.it

1 Internal Medicine Unit for the Treatment of Severe Organ Failure, Dipartimento delle insufficienze d'organo e dei trapianti, IRCCS Azienda Ospedaliero-Universitaria di Bologna, Policlinico di Sant'Orsola, Via Albertoni 15, Bologna, Italy

2 Department of Experimental and Clinical Medicine, University of Florence, Florence, Italy

$\begin{array}{ll}\text { LT } & \text { Liver transplant } \\ \text { MELD } & \text { Mayo clinic end-stage liver disease } \\ \text { MMF } & \text { Mofetil mycophenolate } \\ \text { mTOR } & \text { Mammalian target of rapamycin } \\ \text { NPS } & \text { Naso-pharyngeal swab } \\ \text { SARS-CoV-2 } & \text { Severe acute respiratory syndrome } \\ & \text { Coronavirus-2 } \\ \text { Tacrolimus } & \text { TAC }\end{array}$

\section{Introduction}

In December 2019, a new Coronavirus causing severe acute respiratory syndrome (SARS-CoV-2) was identified in China. The disorder is called coronavirus disease 2019 (COVID-19) [1]. Notably, this viral infection was declared a pandemic by the World Health Organization (WHO) on March 11, 2020. The clinical spectrum of COVID-19 ranges from an asymptomatic state to fatal pneumonia with potential involvement of lungs, heart, and liver [1]. Interestingly, although COVID-19-associated liver injury has been described, the liver generally develops few clinical consequences [1]. However, elevated liver serum blood tests were present in up to $53 \%$ of COVID-19 patients admitted to the hospital [2]. Hypothetical central mechanisms of liver 
injury include immune-mediated damage due to the severe inflammatory response following COVID-19 infection, direct cytotoxicity due to active viral replication in hepatic cells through the angiotensin-converting enzyme 2 (ACE2) ligand expressed in the liver, anoxia in respiratory failure, and finally, drug-induced liver injury. These drugs include antibiotics, nonsteroidal anti-inflammatory drugs, herbs, and some antivirals, such as ribavirin and interferons, and an association with lopinavir-ritonavir modality [2]. The ACE2 receptor is not expressed in Kupffer cells or intrahepatic immune cells [3], which explains that SARS-CoV-2 is generally associated with mild to moderate elevations of liver aminotransaminases in subjects without liver disease. In this setting, abnormality in liver tests upon hospitalization is a negative prognostic factor since these patients present a significantly higher risk of developing severe pneumonia [4]. The critical point for the community of hepatologists and transplantologists is represented by the course of COVID19 in subjects affected by advanced chronic liver disease (ACLD) or liver transplant (LT) recipients.

This group of patients could be considered at risk because they have a chronic disease or because they are taking immunosuppressive drugs, resulting in a more serious virusrelated disease or a worsening of pre-existing liver cirrhosis or reduction in graft survival.

SARS-CoV-2 can indirectly worsen the prognosis of patients with ACLD because of lockdowns and suspension of the usual clinical follow-ups thus resulting in delayed management of liver cirrhosis complications, first of all, hepatocellular carcinoma [5].

Nevertheless, the emergence of COVID-19 has impacted transplantion communities worldwide. Local and international societies for the study of the liver have published several surveys and international position papers on liver cirrhosis and transplant management during the pandemic.

This review analyses the increasing amounts of data that have been collected in recent months concerning the direct and indirect impact of the COVID-19 on patients affected by liver cirrhosis and LT carriers.

\section{Cirrhosis and COVID-19}

\section{Role of the immune system}

Under physiological conditions, the liver plays a key role in the regulation of immune system homeostasis. First, the liver is one of the central protagonists of immune surveillance through the defence against bloodborne pathogens [6]. Second, the liver influences the synthesis of soluble molecules crucial for an active immune response [7].

However, the immune system also has a key role in the pathogenesis of cirrhosis. On the one hand, immune-mediated inflammatory mechanisms concur in the fibrosis progression [8]. On the other, cirrhosis causes an overall weakening of the immune system and an impairment of immune cell activation [8].

For this reason, patients with cirrhosis might be more vulnerable to SARS-CoV-2, and its clinical severity in cirrhotic patients might be higher than in the general population. In general, it is well known that bacterial infections represent one of the main triggers of decompensation in the context of cirrhosis. Nonetheless, data about the potential impact of viral infections concerning the natural history of ACLD are not so extensive and conclusive [9].

Analysing the impact of the influenza virus on cirrhosis could provide some very useful information. In this matter, the H1N1 influenza virus also causes decompensation in cirrhotic patients with stable liver disease [5]. In detail, according to the authors, $82 \%$ of subjects with cirrhosis and A/H1N1/09 die of pneumonia and acute respiratory distress syndrome despite appropriate antiviral therapy [10].

\section{Size of the problem}

Available data from Chinese studies indicate that chronic liver diseases can be diagnosed in $2-11 \%$ of subjects with COVID-19 [11-17]. In Italy, Grasselli et al. [18] reported that among 1591 patients in intensive care units in the Lombardy region, 3\% had a history of liver disease. In patients with COVID-19 who died, liver injury incidence might reach $58-78 \%[19,20]$.

The effects of COVID-19 on the liver can be very different. Remarkably, Cai et al. [21] showed that liver injury occurred more frequently in patients with severe COVID-19 disease than in patients with a mild viral infection.

Patients can frequently develop asymptomatic aminotransferase elevations (14-76\% of cases). This clinical negligible event could result from a primary liver injury or to many indirect effects, such as myositis, toxic liver injury, and/or hypoxia, all of which represent collateral effects of the viral infection. The upsurge of $\gamma$-glutamyl transferase levels and a minimal increase in bilirubin levels are other frequent alterations [22].

Interestingly, the severity of liver damage seems to be proportional to the COVID-19 infection. Indeed, higher aminotransferase levels and lower albumin levels and platelet counts have been described in severe COVID-19 disease compared to mild form. Notably, in the context of pre-existing liver disorder, patients with cirrhosis are at relevant risk of acute-on-chronic liver disease or acute hepatic decompensation [23].

The type of underlying liver disease represents another important prognostic determinant. Patients with non-alcoholic fatty liver disease and subjects with alcohol use disorder present major risks for respiratory disease progression 
than found in other forms of liver disease. This finding can be explained by the high prevalence of respiratory risk factors, such as obesity and smoking habit, found in those patients, respectively [23]. Also, patients with autoimmune liver disease should receive clinical attention for their immunosuppressive regimens. The European Association for the Study of Liver (EASL) [24] recently suggested that decreases in immunosuppressive therapy should be taken into account under special circumstances (such as medication-induced lymphopenia or bacterial/fungal superinfection in cases of severe COVID-19).

\section{Clinical outcome}

Chronic hepatitis does not appear to increase the risk of severe COVID-19 infection [25], whereas, cirrhosis seems to affect patient outcome. Recently, Moon et al. [26] analysed the clinical outcomes of 152 patients with COVID-19 and underlying chronic liver disease (103 and 49 patients with cirrhosis and pre-cirrhotic chronic hepatitis, respectively). Concerning the subgroup with cirrhosis, almost all (95.2\%) were hospitalized with the following outcomes: (1) $23.3 \%$ admitted to intensive care unit (ICU), (2) $17.5 \%$ needed invasive ventilation, (3) $4.9 \%$ require renal replacement therapy, and (4) 39.8\% died. Notably, their mortality rate was higher than non-COVID hospitalized cirrhotic patients [27] and cirrhotic patients with "normal" influenza virus [28].

Considering patients with cirrhosis and COVID-19, the cause of death was lung disease in $78.7 \%$, cardiac-related in $4.3 \%$, and liver-related in $12.2 \%$. In this special context, advanced age, obesity, renal and/or heart disorders, and diabetes were the main death-associated risk factors [29].

Regarding liver-related risk factors, mortality strongly correlated with baseline liver function; specially, deaths occurred in $12.2 \%$ of pre-cirrhotic subjects, $23.9 \%$ with Child-Pugh class A cirrhosis, $43.3 \%$ with class B cirrhosis, and $63 \%$ with class $\mathrm{C}$. Liver function also represented the main predictor of hepatic decompensation (mainly ascites) during COVID infection. Globally, baseline liver disease closely correlated with COVID-19-related morbidity and mortality, although this observation was not confirmed in all the available series. Lopez-Mendez et al. [30] recently reported that the prevalence of steatosis and severe liver fibrosis was higher in COVID-19 patients than in the general population but at the same time, these authors suggested that liver disease did not correlate with the overall clinical outcomes.

It is possible that while pre-cirrhotic chronic hepatitis does not impact overall COVID-related prognosis, cirrhosis in the context of COVID-19 represents a decisive factor of frailty. It is well known that patients with cirrhosis present a considerably higher risk of secondary bacterial infection and a more severe course of influenza comprising multi-organ failure, secondary infections, and death than the general population [28]. Consequently, COVID-19 can barely affect a patient with cirrhosis. In particular, cirrhotic patients might easily develop acute-on-chronic liver failure due to the massive inflammatory responses during the COVID-19 infection [31].

Cirrhosis and COVID-19 can have detrimental effects on each other. For this reason, actions directed to effective prevention should be developed to protect cirrhotic patients. Xiao et al. [32] showed that among 111 patients with decompensated cirrhotic, none developed symptoms suggestive of a SARS-CoV-2 infection when a cautionary attitude was taken. In particular, the authors described protective actions for outpatients, hospital staff training, and new processes for diagnosis, treatment, and emergency strategies.

As recently reported by EASL [24], patients with decompensated cirrhosis should have minimal exposure to medical staff, with the preferential use of telemedicine/visits by phone. If absolutely necessary, in-hospital stays should be as short as possible. The number of consultations, especially external ones, should be reduced. Vaccinations for Streptococcus pneumoniae and influenza represent another important key point for minimizing decompensation in cirrhotic patients.

\section{Awaiting liver transplant}

In this complex and very unusual period, it can be difficult for a transplant centre to manage organ allocation. Centres should constantly evaluate and analyse their local situations and its influence on candidates waiting for transplant [33].

Mortality is likely to increase due to a reduction in suitable donations and drop-outs in patients with a history of decompensated liver disease and hepatocellular carcinoma (HCC) history. Transplant centres might postpone the call for patients with low Mayo Clinic End-stage Liver Disease (MELD) scores, while increasing attention must be directed towards patients who cannot wait, such as those with high MELD and/or HCC. Listing might be limited to patients with a poor short-term prognosis, including those with acute or acute-on-chronic liver failure, high MELD and HCC at the upper limits of the Milan criteria [24].

Particular attention to the mortality risk stratification and organ allocation should also be developed for the potential drop in organ recovery due to institutional resources restrictions [33].

\section{Liver transplantation and COVID-19}

\section{The burden of the question}

Recommendations concerning COVID-19 screening of donors and recipients and transplant policies differ from 
country to country based on population infection rates and available diagnostic resources [34].

The policies of location, procurement, and transport of a deceased person's organs during the COVID-19 pandemic should preserve equity among subjects waiting on the transplant list and reduce the risk of virus spread in healthcare workers and potential recipients.

In this context, the leading transplant societies have released guidelines on donor and LT management $[33,35]$.

Mortality rates could increase during and immediately after an LT due to lack of availability of intensive care units' beds because of an unpreventable new wave of the pandemic; this issues should be addressed for real-time accessible sources, including ventilators and supply of blood products before to perform an LT [33].

Regarding available data related to COVID-19 in LT patients, only a small number of reports and few international multicentre cohorts have been published [36-38].

The impact of comorbidities for mortality has been clearly demonstrated in the general population affected by COVID-19 [39].

Many physicians are confident that patients with chronic liver disease or LT carriers have higher mortality rates after infection with COVID-19. Therefore, they postpone diagnostic tests and procedures.

To the best of our knowledge about SARS-CoV-2 disease evolution, however, risk factors and therapeutic management for specific classes of patients in addition to LT recipients are missing.

Despite their high prevalence of comorbidities among LT carriers, no comorbidities have been independently associated with poor outcome as demonstrated by Belli et al. [37]. Advanced age has been reported to increase mortality risk in COVID-19 patients in preliminary international reports while LT status does not affect mortality [38].

Here, we summarize available data on LT management during the pandemic and the course of SARS-CoV-2 in LT recipients.

\section{Liver transplant protocol}

Most programmes recommend screening deceased donors to prevent the inadvertent transplantation of organs from a SARS-CoV-2-infected donor [40]. A hypothetical risk of transmission of COVID-19 through transplant exists, but to our knowledge, donor-borne transmission has not been described [12].

However, regarding the use of COVID-19-positive living and deceased donors, it is interesting and notable that no recognized SARS-CoV-2 transfusion transmissions have been reported in addition to the absence of SARS-CoV-2 in the liver in a few autopsy studies [41].
Only one case of COVID-19-associated hepatitis in the recipient of an allograft from a living donor positive for COVID-19 has been described [42].

Given the higher sensitivity of alveolar bronchial lavage (BAL) compared to the nasopharyngeal swab (NPS), in the case of a deceased donor, the major international transplant authorities suggest carrying out the specific test for the presence of SARS-CoV-2 on respiratory secretions from BAL or possibly from deep broncho-aspirates, which is offered within 24-48 h before organ retrieval occurs [43].

Since a risk of false negatives exists, especially in asymptomatic COVID-19 carriers, physicians are encouraged to accurately review as much donor history as possible, especially for fever, respiratory symptoms and radiographic findings [33]. In addition to carrying out NPS in living donor LTs, some countries, including Japan, recommend a 14-day isolation period before surgery [34]. Guidelines from the American Association for the Study of Liver Diseases (AASLD) propose accepting only those grafts with a low risk of delayed graft function to reduce complications and post-operative hospitalizations. Donors who tested positive for COVID-19 should be ineligible for organ donation [33].

The organs obtained from COVID-19-positive deceased donors 21-28 days after symptom resolution and two negative NPS $24 \mathrm{~h}$ apart can be used for LT. High-risk donors with suspicious COVID-19 symptoms within 28 days before death should not be used even if the NPS is actually negative [34].

All recipients should then undergo NPS before entering transplant units.

As far as backup transplant recipients, they should stay in a location away from the transplant centre to reduce the risk of a COVID-19 outbreak.

For the same reason, potential recipients must enter the hospital at the latest possible time to minimize potential exposure to COVID-19. Family members should be forbidden to enter the ward during the entire hospitalization period [33]. When the donor's results for the COVID-19 tests are known, recipients admitted for LT should complete a screening for symptoms of SARS-CoV-2 or recent exposure, including the presence of a fever, cough, shortness of breath, sore throat, diarrhoea, recent loss of sense of taste or smell, contact with known COVID-19 carriers, and recent travel history.

Since recipients have an immunocompromised status, they are at higher risk of contracting COVID-19 infection, and the reduction of dissemination of infection to other spreaders, especially healthcare workers, plays a key role in the recipient's status. Up to $20 \%$ of healthcare workers taking care of patients with COVID-19 can becomes infected [44].

So, protocols to contain SARS-CoV-2 infection and strategies of vaccination against SARS-CoV-2 in healthcare 
personnel are needed to guarantee the healthcare systems function efficiently, including sufficient intensive care unit beds and healthcare workers $[33,45]$.

The application of rigid protocols to prevent the spread of COVID-19 has allowed some centres to conduct transplant activity without decreasing the number of LTs performed or increasing the mortality in the patients who underwent transplants [43].

\section{Immunosoppressants and SARS-CoV-2}

Considering data collected from experiences with other viral infections, immunosuppressed patients are generally deemed at increased risk of severe clinical manifestations and worse outcomes than the general population [34].

However, univocal data on the course of COVID-19 in LT patients are lacking; if recently transplanted patients do not seem to present greater COVID-19 mortality-related risks than the general population, long-term transplant recipients have a worse course, probably due to the more frequent presence of metabolic disorders such as obesity, diabetes, kidney diseases, and arterial hypertension [46].

On the other hand, immunosuppressive drugs may delay viral clearance in post-transplant patients who have contracted COVID-19 [47].

The AASLD and EASL suggest minimising high doses of prednisone, azathioprine, or mycophenolate, especially in the setting of lymphopenia and reducing, but not stopping, daily calcineurin inhibitor (CNI) dosages, except in severe cases of bacterial or fungal infections superimposed on COVID-19 due to the risk of acute rejection in patients with COVID-19. Immunosuppression seems to play a protective role against SARS-CoV-2 infection [24] EASL underlies the importance of vaccination for $S$. pneumoniae and influenza [24]. Drug levels of CNI and mammalian target of rapamycin (mTOR) inhibitors should be routinely tested since the risk of drug-to-drug interactions, such as antivirals and antibiotics, exists [48]

In an international cohort of 243 symptomatic adult cases collected in Europe, use of tacrolimus (TAC) was associated with a reduced mortality risk [37], and no beneficial effect of the cyclosporin A (CsA), another CNI, was found. The two drugs have similar functions but different mechanisms of action.

LT patients receiving TAC are generally younger and have fewer comorbidities; thus, this condition could represent a confounding factor. In this study, however, the authors considered the comparison between patients receiving TAC and no TAC with respect to some relevant clinical variables, such as age, time from transplant, chronic renal failure, concurrent exposure to angiotensin-converting enzyme inhibitors, or angiotensin II receptor blockers, and the presence of HCC.
TAC was shown to play an independent protective role, considering the variables cited above [37].

The potential protective effects of TAC are not clear. The most credible hypotheses for its actions are inhibition of viral replication and/or interactions with immune responses. TAC can inhibit the replication of some of the human coronaviruses, notably SARS-CoV- 1 , probably by binding some immunophyllin pathways. TAC has not been shown to specifically inhibit replication of SARS-CoV-2 [49, 50]. Furthermore, CNI, including TAC, can play a key role through their immunosuppressive properties in suppressing the early phase of T-cell activation and causing secondary production of many cytokines, notably pro-inflammatory cytokines, in addition to tumour necrosis factor and interferon gamma (TNF and IFN $\gamma$, respectively) increases in severe COVID19 forms [51].

Although TAC and CsA both have potential benefits in treating certain viral diseases, Ruiiz [52] tried to explain the loss of a protective role of CsA compared with TAC the study by Belli [37] after considering some parameters in a group of patients receiving CSA. These factors included the major predominance of older, males subjects and higher median time between LT and COVID-19 infection, which implies a lower residual concentration of immunosuppressor directly related to the effect in the infection and lower percentage (but not significant) of patient receiving steroids who demonstrated anti-inflammatory properties, and finally a higher percentage of patients co-treated with mycophenolate mofetil (MMF) [52].

Therefore, pending confirmative data about the protective role of TAC compared to the recommendations in the main international guidelines on the reduction of immunosuppressive therapy during SARS-CoV-2 infection, modifications of the TAC dose should be discouraged in LT.

Based on the intracellular mechanisms of CNIs, a similar beneficial effect could be expected for CsA, so a reduction in therapy during SARS-CoV-2 infection is not recommended.

Few studies are available concerning the use of MMF in Middle East respiratory syndrome coronavirus (MERS$\mathrm{CoV})$, but high viral loads with more severe or even fatal disease were reported [53].

Instead, MMF use can explains that abdominal symptoms, especially diarrhoea, are at least twice more frequent than in the general population with COVID-19 [36].

These data were confirmed by Belli et al. [37] in which almost $50 \%$ of the 26 patients who received MMF as the main immunosuppressant had diarrhoea as the first symptom [37].

Thus, physicians should suspect SARS-CoV2-disease performing NPS in LT carriers immunosuppressed by MMF with new-onset diarrhoea.

For these reasons, MMF was often the most discontinued immunosuppressant therapy [36]. 
Experiences with other viral infections (hepatitis $\mathrm{C}$, cytomegalovirus) suggest a potential benefit in that management of immunosuppression without MMF or inhibitors of mTOR since these drugs are also associated with leukopenia and lymphopenia [54].

Concerning the use of mTOR inhibitors, no robust data on their protective role against COVID-19 in clinical practice are available to date [54].

However, the antiviral properties of mTOR inhibitors have been described against the most prevalent viruses in addition to cytomegalovirus infection and human herpesvirus eight-related Kaposi sarcoma. Various mechanisms for this agent's activity have been proposed: (1) mTOR inhibitors increase the efficacy of memory T-cells in response to vaccines and viral antigens, (2) they inhibit viral cell growth through an antiapoptotic protein kinase B pathway (Akt pathway) via inhibition of viral protein synthesis (pUL44 and pp65 for CMV replication in macrophages), and (3) interfering with virus-mediated transcriptional events [55]. In a small, randomised controlled trial, treatment with sirolimus compared to no sirolimus in 28 critical patients with influenza $\mathrm{A}(\mathrm{H} 1 \mathrm{~N} 1)$ pneumonia undergoing invasive mechanical ventilation (in addition to oseltamivir and corticosteroids) led to an improvement in hypoxia, multiple organ dysfunction, and virus clearance in addition to a reduction in the duration of mechanical ventilation [56].

Interestingly, an antiviral drug repurposing approach capable of identifying the existing drugs and potentially effective against COVID-19 has been proposed. Furthermore, using an analytic system to quantify the interplay between the human coronaviruses-host interactome and drug targets in the human protein-protein interaction network, some potentially effective drugs have been identified. Sirolimus in combination with dactinomycin is one of three potential drug combinations that has been found [57]. Therefore, there seems to be a rationale for proposing studies concerning the use of sirolimus in infected-COVID-19 transplant patients.

Continuation of pre-existing maintenance everolimus immunosuppression should therefore be considered in transplant recipients who have contracted SARS-CoV-2.

Finally, corticosteroids are considered a cornerstone in the therapy of severe forms of COVID-19 disease since their anti-inflammatory effects should mitigate the cytokine storm reducing the lung injury and the multisystem organ dysfunction. Dexamethasone, administered up to ten days after infection diagnosis caused a reduction in mortality from COVID-19 in the randomized multicentre open label RECOVERY trial when compared with the standard of care [58].

In the COVID-19 LT population, use of corticosteroids is complex with respect to the difficult balance between the downregulation of inflammatory immune system response and the risk of fatal opportunistic infections.

Since no advantages of dexamethasone were observed in patients who did not require supplemental oxygen [58], chronic low doses of long-term steroid-based therapies should not be increased in LT patients.

Although significant reports have been published about the LT population, many limitations are still present: (1) retrospective studies, (2) lack of information on immunosuppressant levels upon hospitalization and their management, (3) lack of information about cortisone-based therapies used and rates of bacterial and fungal infections that occurred, (4) lack of information about home-based therapies, and (5) lack of information about concomitant diseases and risk factors, including smoking and lung illnesses.

Generally, remodulation of immunosuppressive treatment should only be considered case by case under special circumstances, such us medication-induced lymphopenia or bacterial/fungal superinfection in case of severe COVID-19 in addition to graft rejection risk according to the referring LT centre [24].

\section{Liver transplant outcomes and SARS-CoV-2}

Despite concerns that LT status may present an increased risk of unfavourable outcomes from SARS-CoV-2 due the high prevalence of old age, co-diseases, acquired immunosuppressive state, no clear information about this risk has been found.

Data collected from two international registries (COVIDHep and SECURE-Cirrhosis) concerning 151 adult LT recipients from 18 countries compared with 627 patients who had not undergone LT showed that the two groups did not differ with regard to the proportion of patients hospitalized (82\% in LT cohort versus $76 \%$ in the comparison cohort), while $19 \%$ LT recipients died compared with $27 \%$ in the other cohort $(p=0 \cdot 046)$. In the propensity score-matched analysis (adjusted for age, sex, creatinine concentration, obesity, hypertension, diabetes, and ethnicity), LT did not cause a significant increase in the risk of death in patients with SARS-CoV-2 infection. Unfavourable outcomes among LT patients were associated with age, kidney diseases, and nonliver cancer [38].

Belli et al. [37] reported similar fatality rates in an international study on 243 adult LT symptomatic cases collected in Europe in which 204 LT patients (84\%) required hospitalization, 39 were admitted to the intensive care unit $(19.1 \%)$, and $14(20.2 \%)$ patients died as a result of respiratory failure as the major cause. Factors significantly associated with death by univariable analysis were increased recipient age, time from LT, diabetes, chronic kidney disease, number of comorbidities. Advanced age ( $>70$ years versus $<60$ years) remained independently associated with an increased 
fourfold mortality risk while use of TAC was associated with a reduced mortality risk (hazard ratio [HR] 0.55 ; $95 \%$ confidence interval [CI] 0.31-0.99) in a multivariable analysis.

A history of cancer was confirmed be a risk factor for death as shown in another European multicentre prospective study among 57 LT recipients. In that study, COVID-19 was found to be associated with an overall and in-hospital fatality rate of $12 \%$ (95\% CI 5-24\%) and 17\% (95\% CI 7-32\%), respectively. Interestingly, in this study the reduction or withdrawal of immunosuppressant had no impact on poorer outcome [36].

In summary, LT status and secondary acquired immunosuppression do not appear to be risk factors for poor prognosis in this population in which older age, comorbidities such as diabetes, renal failure, and history of cancer appear to occur [36-38].

\section{Conclusions}

The evolution of COVID-19 disease in subjects affected by ACLD or LT transplant carriers remains the main question for the community of hepatologists and transplant physicians. ACLD and LT recipients should be considered at risk because they have a chronic disease or because they are taking immunosuppressive drugs, resulting in a more serious virus-related disease or a worsening of preexistent liver cirrhosis and a reduction in graft survival. Initial beliefs regarding LT status as a risk factor have been partially disproven, while they have been confirmed for patients with ACLD. COVID-19 is associated with worsening liver function and elevated mortality in patients with cirrhosis; mortality rates resulted significantly higher than those hospitalized for bacterial infections.

This finding is explained by the fact that stress and sepsis are particularly prominent in patients with ACLD as either one can trigger acute-on-chronic liver failure; a significant inflammatory status activated by COVID-19 induces hepatocyte necrosis in the context of an already reduced functional reserve.

SARS-CoV-2 can indirectly cause a worsening of the prognosis of ACLD patients because of lockdowns and suspension of usual clinical follow-ups resulting in delayed management of liver cirrhosis complications, such as HCC.

Furthermore, in the next years and decades, liver-related mortality and morbidity is likely to increase because of the global economic crisis and social isolation for which an increase in alcohol and drug use with bloodborne virus transmissions are predictable, and access to care will be limited due to the collapse in healthcare and support structures.

Concerning LT management, liver society position papers that are based on the general approach to transplant recipients with an active infection, and expert opinions that minimise immunosuppression are routinely suggested.

In contrast to what was believed at the beginning of the pandemic, LT recipients should not be considered among the categories at greatest risk of death.

Systematic reduction or withdrawal of immunosuppressive therapy is not justified although in some cases, it appears to have a protective action against the inflammatory cascade induced by SARS-CoV-2. CNI, especially TAC, show more evidence of a beneficial role in treating SARS-CoV-2. However, a change in immunosuppressive therapy at the time of COVID-19 infection is not justified, and the start or choice dosage of corticosteroids to be used requires a careful balance of the risks of bacterial and fungal superinfections.

Finally, the use of not well evidenced-based drugs against COVID-19 should be carefully considered in LT since their potential interactions with immunosuppressive treatment and the resulting risk of graft rejection or toxicity exists.

Author contributions Conceptualization: GV, SG; methodology: SG, FM; resources: MCM, GV; supervision: MCM, FM; writing-original draft: GV, SG; writing—review and editing: GV, SG, FM.

Funding This manuscript has not been funded.

\section{Declarations}

Conflict of interest The authors have no relevant affiliations or financial involvement with any organization or entity with a financial interest in or financial conflict with the subject matter or materials discussed in the manuscript.

Human and animal rights statement Not applicable.

Informed consent Not applicable.

\section{References}

1. Pawlotsky JM (2020) COVID-19 and the liver-related deaths to come. Nat Rev Gastroenterol Hepatol 17(9):523-525. https://doi. org/10.1038/s41575-020-0328-2

2. Sun J, Aghemo A, Forner A, Valenti L (2020) COVID-19 and liver disease. Liver Int 40(6):1278-1281. https://doi.org/10.1111/liv. 14470

3. Qi F, Qian S, Zhang S, Zhang Z (2020) Single cell RNA sequencing of 13 human tissues identify cell types and receptors of human coronaviruses. Biochem Biophys Res Commun 526(1):135-140. https://doi.org/10.1016/j.bbrc.2020.03.044 (Epub 2020 Mar 19)

4. Cai Q, Huang D, Yu H, Zhu Z, Xia Z, Su Y, Li Z, Zhou G, Gou J, Qu J, Sun Y, Liu Y, He Q, Chen J, Liu L, Xu L, COVID-19 (2020) Abnormal liver function tests. J Hepatol 73(3):566-574. https:// doi.org/10.1016/j.jhep.2020.04.006 (Epub 2020 Apr 13)

5. Tapper EB, Asrani SK (2020) The COVID-19 pandemic will have a long-lasting impact on the quality of cirrhosis care. J Hepatol 
73(2):441-445. https://doi.org/10.1016/j.jhep.2020.04.005 (Epub 2020 Apr 13)

6. Jenne CN, Kubes P (2013) Immune surveillance by the liver. Nat Immunol 14(10):996-1006. https://doi.org/10.1038/ni.2691

7. Racanelli V, Rehermann B (2006) The liver as an immunological organ. Hepatology 43(2 Suppl 1):S54-62. https://doi.org/10.1002/ hep. 21060

8. Albillos A, Lario M, Álvarez-Mon M (2014) Cirrhosis-associated immune dysfunction: distinctive features and clinical relevance. J Hepatol 61(6):1385-1396. https://doi.org/10.1016/j.jhep.2014. 08.010

9. Piano S, Brocca A, Mareso S, Angeli P (2018) Infections complicating cirrhosis. Liver Int 38(Suppl 1):126

10. Premkumar M, Devurgowda D, Dudha S, Maiwall R, Bihari C, Grover S, Gupta E, Kumar S, Sarin SK (2019) A/H1N1/09 Influenza is associated with high mortality in liver cirrhosis. J Clin Exp Hepatol 9(2):162-170. https://doi.org/10.1016/j.jceh.2018.04.006

11. Yue H, Bai X, Wang J, Yu Q, Liu W, Pu J, Wang X, Hu J, Xu D, Li X, Kang N, Li L, Lu W, Feng T, Ding L, Li X, Qi X, Gansu Provincial Medical Treatment Expert Group of COVID-19 (2020) Clinical characteristics of coronavirus disease 2019 in Gansu province, China. Ann Palliat Med 9(4):1404-1412. https://doi. org/10.2137/apm-20-887

12. Huang C, Wang Y, Li X, Ren L, Zhao J, Hu Y, Zhang L, Fan G, Xu J, Gu X, Cheng Z, Yu T, Xia J, Wei Y, Wu W, Xie X, Yin W, Li H, Liu M, Xiao Y, Gao H, Guo L, Xie J, Wang G, Jiang R, Gao Z, Jin Q, Wang J, Cao B (2020) Clinical features of patients infected with 2019 novel coronavirus in Wuhan, China. Lancet 395(10223):497-506. https://doi.org/10.1016/S0140-6736(20) 30183-5

13. Chen N, Zhou M, Dong X, Qu J, Gong F, Han Y, Qiu Y, Wang J, Liu Y, Wei Y, Xia J, Yu T, Zhang X, Zhang L (2020) Epidemiological and clinical characteristics of 99 cases of 2019 novel coronavirus pneumonia in Wuhan, China: a descriptive study. Lancet 395(10223):507-513. https://doi.org/10.1016/S0140-6736(20) 30211-7

14. Wang D, Hu B, Hu C, Zhu F, Liu X, Zhang J, Wang B, Xiang H, Cheng Z, Xiong Y, Zhao Y, Li Y, Wang X, Peng Z (2020) Clinical characteristics of 138 hospitalized patients with 2019 novel coronavirus-infected pneumonia in Wuhan, China. JAMA 323(11):1061-1069. https://doi.org/10.1001/jama.2020.1585

15. Shi H, Han X, Jiang N, Cao Y, Alwalid O, Gu J, Fan Y, Zheng C (2020) Radiological findings from 81 patients with COVID-19 pneumonia in Wuhan, China: a descriptive study. Lancet Infect Dis 20(4):425-434. https://doi.org/10.1016/S1473-3099(20) 30086-4

16. Xu XW, Wu XX, Jiang XG, Xu KJ, Ying LJ, Ma CL, Li SB, Wang HY, Zhang S, Gao HN, Sheng JF, Cai HL, Qiu YQ, Li LJ (2020) Clinical findings in a group of patients infected with the 2019 novel coronavirus (SARS-Cov-2) outside of Wuhan, China: retrospective case series. BMJ 368:606. https://doi.org/10.1136/ bmj.m606 (Erratum in BMJ; 368:m792)

17. Yang X, Yu Y, Xu J, Shu H, Xia J, Liu H, Wu Y, Zhang L, Yu Z, Fang M, Yu T, Wang Y, Pan S, Zou X, Yuan S, Shang Y (2020) Clinical course and outcomes of critically ill patients with SARSCoV-2 pneumonia in Wuhan, China: a single-centered, retrospective, observational study. Lancet Respir Med 8(5):475-481. https://doi.org/10.1016/S2213-2600(20)30079-5

18. Grasselli G, Zangrillo A, Zanella A, Antonelli M, Cabrini L, Castelli A, Cereda D, Coluccello A, Foti G, Fumagalli R, Iotti G, Latronico N, Lorini L, Merler S, Natalini G, Piatti A, Ranieri MV, Scandroglio AM, Storti E, Cecconi M, Pesenti A, COVID19 Lombardy ICU Network (2020) Baseline characteristics and outcomes of 1591 patients infected with SARS-CoV-2 admitted to ICUs of the Lombardy Region, Italy. JAMA 323(16):1574-1581. https://doi.org/10.1001/jama.2020.5394
19. Huang Y, Yang R, Xu Y, Gong P (2020) Clinical characteristics of 36 nonsurvivors with COVID-19 in Wuhan, China. Preprint (2020). medRxiv 2020.02.27.20029009. https//doi.org/https:// doi.org/10.1101/2020.02.27.20029009.

20. Zhang B, Zhou X, Qiu Y, Feng F, Feng J, Jia Y, Zhu H, Hu K, Liu J, Liu Z, Wang S, Gong Y, Zhou C, Zhu T, Cheng Y, Liu Z, Deng H, Tao F, Ren Y, Cheng B, Gao L, Wu X, Yu L, HuangnZ, Mao Z, Song Q, Zhu B (2020) View ORCID Profile Jun Wang Clinical characteristics of 82 death cases with COVID-19. Preprint 2020. medRxiv 2020.02.26.20028191. https://doi.org/10. 1101/2020.02.26.20028191.

21. Cai J, Xu J, Lin D, Zhi Y, Lei X, Zhenghai Q, Yuehua Q, Hua Z, Ran J, Pengcheng L, Xiangshi W, Yanling G, Aimei X, He T, Hailing C, Chuning W, Jingjing L, Jianshe W, Mei Z (2020) A case series of children with 2019 novel coronavirus infection: clinical and epidemiological features. Clin Infect Dis 71(6):1547-1551. https://doi.org/10.1093/cid/ciaa198

22. Fan Z, Chen L, Li J, Cheng X, Yang J, Tian C, Zhang Y, Huang S, Liu Z, Cheng J (2020) Clinical features of COVID-19-related liver functional abnormality. Clin Gastroenterol Hepatol 18(7):1561-1566. https://doi.org/10.1016/j.cgh.2020.04.002

23. Hamid S, Alvares da Silva MR, Burak KW, Chen T, Drenth JPH, Esmat G, Gaspar R, LaBrecque D, Lee A, Macedo G, McMahon B, Ning Q, Reau N, Sonderup M, van Leeuwen DJ, Armstrong D, Yurdaydin C (2021) WGO guidance for the care of patients with COVID-19 and liver disease. J Clin Gastroenterol 55(1):1-11. https://doi.org/10.1097/MCG.0000000000 001459

24. Boettler T, Newsome PN, Mondelli MU, Maticic M, Cordero E, Cornberg M, Berg T (2020) Care of patients with liver disease during the COVID-19 pandemic: EASL-ESCMID position paper. JHEP Rep 2(3):100113. https://doi.org/10.1016/j.jhepr.2020

25. Guan WJ, Ni ZY, Hu Y, Liang WH, Ou CQ, He JX, Liu L, Shan H, Lei CL, Hui DSC, Du B, Li LJ, Zeng G, Yuen KY, Chen RC, Tang CL, Wang T, Chen PY, Xiang J, Li SY, Wang JL, Liang ZJ, Peng YX, Wei L, Liu Y, Hu YH, Peng P, Wang JM, Liu JY, Chen Z, Li G, Zheng ZJ, Qiu SQ, Luo J, Ye CJ, Zhu SY, Zhong NS, China Medical Treatment Expert Group for Covid-19 (2020) Clinical characteristics of coronavirus disease 2019 in China. N Engl J Med 382:1708-1720. https://doi.org/10.1056/NEJMoa2002 032

26. Moon AM, Webb GJ, Aloman C, Armstrong MJ, Cargill T, Dhanasekaran R, Genescà J, Gill US, James TW, Jones PD, Marshall A, Mells G, Perumalswami PV, Qi X, Su F, Ufere NN, Barnes E, Barritt AS, Marjot T (2020) High mortality rates for SARS$\mathrm{CoV}-2$ infection in patients with pre-existing chronic liver disease and cirrhosis: preliminary results from an international registry. J Hepatol 73(3):705-708. https://doi.org/10.1016/j.jhep.2020.05. 013

27. Schmidt ML, Barritt AS, Orman ES, Hayashi PH (2015) Decreasing mortality among patients hospitalized with cirrhosis in the United States from 2002 through 2010. Gastroenterology 148(5):967-977.e2. https://doi.org/10.1053/j.gastro.2015.01.032

28. Schütte A, Ciesek S, Wedemeyer H, Lange CM (2019) Influenza virus infection as precipitating event of acute-on-chronic liver failure. J Hepatol 70(4):797-799. https://doi.org/10.1016/j.jhep. 2018.11.015

29. Zhou F, Yu T, Du R, Fan G, Liu Y, Liu Z, Xiang J, Wang Y, Song B, Gu X, Guan L, Wei Y, Li H, Wu X, Xu J, Tu S, Zhang Y, Chen H, Cao B (2020) Clinical course and risk factors for mortality of adult inpatients with COVID-19 in Wuhan, China: a retrospective cohort study. Lancet 395(10229):1054-1062. https://doi.org/10. 1016/S0140-6736(20)30566-3

30. Lopez-Mendez I, Aquino-Matus J, Gall SM, Prieto-Nava JD, Juarez-Hernandez E, Uribe M, Castro-Narro G (2020) Association of liver steatosis and fibrosis with clinical outcomes in 
patients with SARS-CoV-2 infection (COVID-19). Ann Hepatol 20:100271. https://doi.org/10.1016/j.aohep.2020.09.015

31. Strnad P, Tacke F, Koch A, Trautwein C (2017) Liver -guardian, modifier and target of sepsis. Nat Rev Gastroenterol Hepatol 14:55-66. https://doi.org/10.1038/nrgastro.2016.168

32. Xiao Y, Pan H, She Q, Wang F, Chen M (2020) Prevention of SARSCoV-2 infection in patients with decompensated cirrhosis. Lancet Gastroenterol Hepatol 5:528-529. https://doi.org/10.1016/ S2468-1253(20)30080-7

33. Fix OK, Hameed B, Fontana RJ, Kwok RM, McGuire BM, Mulligan DC, Pratt DS, Russo MW, Schilsky ML, Verna EC, Loomba R, Cohen DE, Bezerra JA, Rajender Reddy K, Chung RT (2020) Clinical best practice advice for hepatology and liver transplant providers during the COVID-19 pandemic: AASLD Expert Panel Consensus Statement. Hepatology 72(1):287-304. https://doi.org/ 10.1002/hep. 31281

34. Kumar D, Manuel O, Natori Y, Egawa H, Grossi P, Han SH, Fernández-Ruiz M, Humar A (2020) COVID-19: A global transplant perspective on successfully navigating a pandemic. Am J Transplant 20(7):1773-1779. https://doi.org/10.1111/ajt.15876 (Epub 2020 Apr 12)

35. Ahn C, Amer H, Anglicheau D, Ascher NL, Baan CC, Battsetset G, Bat-Ireedui B, Berney T, Betjes MGH, Bichu S, Birn H, Brennan D, Bromberg J, Caillard S, Cannon RM, Cantarovich M, Chan A, Chen ZS, Chapman JR, Cole EH, Cross N, Durand F, Egawa H, Emond JC, Farrero M, Friend PJ, Geissler EK, Ha J, Haberal MA, Henderson ML, Hesselink DA, Humar A, Jassem W, Jeong JC, Kaplan B, Kee T, Kim SJ, Kumar D, Legendre CM, Man K, Moulin B, Muller E, Munkhbat R, Od-Erdene L, Perrin P, Rela M, Tanabe K, Tedesco Silva H, Tinckam KT, Tullius SG, Wong G (2020) Global transplantation COVID report march 2020. Transplantation 104(10):1974-1983. https://doi.org/10.1097/TP.00000 00000003258

36. Becchetti C, Zambelli MF, Pasulo L, Donato MF, Invernizzi F, Detry O, Dahlqvist G, Ciccarelli O, Morelli MC, Fraga M, Svegliati-Baroni G, van Vlierberghe $\mathrm{H}$, Coenraad MJ, Romero MC, de Gottardi A, Toniutto P, Del Prete L, Abbati C, Samuel D, Pirenne J, Nevens F, Dufour J-F, COVID-LT group (2020) COVID-19 in an international European liver transplant recipient cohort. Gut. https://doi.org/10.1136/gutjnl-2020-321923 (Online ahead of print)

37. Belli LS, Fondevila C, Cortesi PA, Conti S, Karam V, Adam R, Coilly A, Ericzon BG, Loinaz C, Cuervas-Mons V, Zambelli M, Llado L, Diaz F, Invernizzi F, Patrono D, Faitot F, Bhooori S, Pirenne J, Perricone G, Magini G, Castells L, Detry O, Cruchaga PM, Colmenero J, Berrevoet F, Rodriguez G, Ysebaert D, Radenne S, Metselaar H, Morelli C, De Carlis L, Polak WG, Duvoux C, ELITA-ELTR COVID-19 Registry (2020) Protective role of tacrolimus, deleterious role of age and comorbidities in liver transplant recipients with COVID-19: results from the ELITA/ELTR multi-center European study. Gastroenterology. https://doi.org/10.1053/j.gastro.2020.11.045

38. Webb GJ, Moon AM, Barnes E, Barritt AS 4th, Marjot T (2021) Age and comorbidity are central to the risk of death from COVID19 in liver transplant recipients. J Hepatol 8:8-78. https://doi.org/ 10.1016/j.jhep.2021.01.036 (Epub ahead of print)

39. Guan WJ, Liang WH, Zhao Y, Liang HR, Chen ZS, Li YM, Liu XQ, Chen RC, Tang CL, Wang T, Ou CQ, Li L, Chen PY, Sang L, Wang W, Li JF, Li CC, Ou LM, Cheng B, Xiong S, Ni ZY, Xiang J, Hu Y, Liu L, Shan H, Lei CL, Peng YX, Wei L, Liu Y, Hu YH, Peng P, Wang JM, Liu JY, Chen Z, Li G, Zheng ZJ, Qiu SQ, Luo J, Ye CJ, Zhu SY, Cheng LL, Ye F, Li SY, Zheng JP, Zhang NF, Zhong NS, He JX, China Medical Treatment Expert Group for COVID-19 (2020) Comorbidity and its impact on 1590 patients with COVID-19 in China: a nationwide analysis. Eur Respir J 55(5):2000547. https://doi.org/10.1183/13993003.00547-2020
40. Ritschl PV, Nevermann N, Wiering L, Wu HH, Moroder P, Brandl A, Hillebrandt K, Tacke F, Friedersdorff F, Schlomm T, Schöning W, Öllinger R, Schmelzle M, Pratschke J (2020) Solid organ transplantation programs facing lack of empiric evidence in the COVID-19 pandemic: a by-proxy society recommendation consensus approach. Am J Transplant 20(7):1826-1836. https://doi. org/10.1111/ajt.15933

41. Kates OS, Fisher CE, Rakita RM, Reyes JD, Limaye AP (2020) Emerging evidence to support not always "just saying no" to SARS-CoV-2 positive donors. Am J Transplant 20(11):32613262. https://doi.org/10.1111/ajt.16119 (Epub 2020 Jun 18)

42. Di Maira T, Berenguer M (2020) COVID-19 and liver transplantation. Nat Rev Gastroenterol Hepatol 17(9):526-528. https://doi. org/10.1038/s41575-020-0347-z

43. Siniscalchi A, Vitale G, Morelli MC, Ravaioli M, Laici C, Bianchini A, Del Gaudio M, Conti F, Vizioli L, Cescon M (2020) Liver transplantation in Italy in the era of COVID 19: reorganizing critical care of recipients. Intern Emerg Med 15(8):1507-1515. https://doi.org/10.1007/s11739-020-02511-z (Epub 2020 Sep 26)

44. Remuzzi A (2020) COVID-19 and Italy: what next? Lancet. https://doi.org/10.1016/S0140-6736(20)30627-9

45. Labetoulle R, Detoc M, Gagnaire J, Berthelot P, Pelissier C, Fontana L, Botelho-Nevers E, Gagneux-Brunon A (2020) COVID-19 in health-care workers: lessons from SARS and MERS epidemics and perspectives for chemoprophylaxis and vaccines. Expert Rev Vaccines 19(10):937-947. https://doi.org/10.1080/14760584. 2020.1843432

46. Bhoori S, Rossi RE, Citterio D, Mazzaferro V (2020) COVID-19 in long-term liver transplant patients: preliminary experience from an Italian transplant centre in Lombardy. Lancet Gastroenterol Hepatol 5(6):532-533. https://doi.org/10.1016/S2468-1253(20) 30116-3

47. Qin J, Wang H, Qin X, Zhang P, Zhu L, Cai J, Yuan Y, Li H (2020) Perioperative presentation of COVID-19 disease in a liver transplant recipient. Hepatology. https://doi.org/10.1002/hep. 31257

48. Bollipo S, Kapuria D, Rabiee A, Ben-Yakov G, Lui RN, Lee HW, Kumar G, Siau K, Turnes J, Dhanasekaran R (2020) One world, one pandemic, many guidelines: management of liver diseases during COVID-19. Gut 69(8):1369-1372. https://doi.org/10.1136/ gutjnl-2020-321553 (Epub 2020 Jun 4)

49. Carbajo-Lozoya J, Müller MA, Kallies S, Thiel V, Drosten C, von Brunn A (2012) Replication of human coronaviruses SARS-CoV, HCoV-NL63 and HCoV-229E is inhibited by the drug FK506. Virus Res 165(1):112-117. https://doi.org/10.1016/j.virusres. 2012.02.002

50. Tanaka Y, Sato Y, Sasaki T (2013) Suppression of coronavirus replication by cyclophilin inhibitors. Viruses 5:1250-1260. https://doi.org/10.3390/v5051250

51. Willicombe M, Thomas D, McAdoo S (2020) COVID-19 and calcineurin inhibitors: should they get left out in the storm? J Am Soc Nephrol 31(6):1145-1146. https://doi.org/10.1681/ASN. 2020030348 (Epub 2020 Apr 20)

52. Ruiz I (2021) Beneficial effect of tacrolimus...Cyclosporin A, still up for discussion! Gastroenterology 16:5-85. https://doi.org/10. 1053/j.gastro.2021.02.039 (Epub ahead of print)

53. Chan JF, Yao Y, Yeung ML, Deng W, Bao L, Jia L, Li F, Xiao C, Gao H, Yu P, Cai JP, Chu H, Zhou J, Chen H, Qin C, Yuen KY (2015) Treatment with Lopinavir/Ritonavir or Interferon- $\beta 1 b$ improves outcome of MERS-CoV infection in a nonhuman primate model of common marmoset. J Infect Dis 212(12):19041913. https://doi.org/10.1093/infdis/jiv392 (Epub 2015 Jul 21)

54. Forns X, Navasa M (2020) Liver transplant immunosuppression during the covid-19 pandemic. Gastroenterol Hepatol 43(8):457463. https://doi.org/10.1016/j.gastrohep.2020.06.003 (English, Spanish) 
55. Bowman L, Brueckner AJ, Doligalski CT (2018) The role of mTOR inhibitors in the management of viral infections: a review of current literature. Transplantation 102:S50-S59. https://doi. org/10.1097/TP.0000000000001777

56. Wang CH, Chung FT, Lin SM, Huang SY, Chou CL, Lee KJ, Lin TY, Kuo HP (2014) Adjuvant treatment with a mammalian target of rapamycin inhibitor, sirolimus, and steroids improves outcomes in patients with severe H1N1 pneumonia and acute respiratory failure. Crit Care Med 42:313-321. https://doi.org/10.1097/CCM. 0b013e3182a2727d

57. Zhou Y, Hou Y, Shen J, Huang Y, Martin W, Cheng F (2020) Network-based drug repurposing for novel coronavirus 2019nCoV/SARS-CoV-2. Cell Discov 6:14. https://doi.org/10.1038/ s41421-020-0153-3
58. RECOVERY Collaborative Group, Horby P, Lim WS, Emberson JR, Mafham M, Bell JL, Linsell L, Staplin N, Brightling C, Ustianowski A, Elmahi E, Prudon B, Green C, Felton T, Chadwick D, Rege K, Fegan C, Chappell LC, Faust SN, Jaki T, Jeffery K, Montgomery A, Rowan K, Juszczak E, Baillie JK, Haynes R, Landray MJ (2021) Dexamethasone in hospitalized patients with COVID-19. N Engl J Med 384(8):693-704. https://doi.org/10. 1056/NEJMoa2021436 (Epub 2020 Jul 17)

Publisher's Note Springer Nature remains neutral with regard to jurisdictional claims in published maps and institutional affiliations. 